history and philosophy of the science. The suggestion that evolutionary psychology and psychiatry has been created over the past 20 years is surprising.

I would suggest that its origins are far more venerable and lie in the work of Ernst Haeckel (1834-1919), sometime Professor of Zoology at the University of Jena, who dominated the discussion of evolutionary theory in German-speaking Europe in the 19th century and who, indeed, published his theory of human evolution in 1868 (see Haeckel, 1879), 3 years prior to Darwin's The Descent of Man (1871). He is now perhaps best remembered for his 'biogenetic law' (i.e. that ontology recapitulates phylogeny). For human beings this means that the stages of human development replicate, in sequence, the stages of the development of the human race. In addition to biological recapitulation, Haeckel considered that the mind had also evolved and that one of the tasks of psychology was to trace this evolution.

The task was initially taken up by Freud (1950) and by Jung (1953), who started to compile historical evidence for his hypothesis of the collective unconscious in 1909. Indeed, throughout the Collected Works it is clear that Jung considered that ontogenesis in psychology corresponded to phylogenesis and that infantile thinking, as well as dreams, were "a re-echo of the prehistoric and the ancient".

Abed, R.T. (2000) Psychiatry and Darwinism. British Journal of Psychiatry, 177, I-3.

Darwin, C. R. (187I) The Descent of Man, and Selection in Relation to Sex. London: John Murray.

Freud, S. (1950) Totem and Taboo: Resemblances between the Psychic Lives of Savages and Neurotics. Reprinted (1953-1974) in the Standard Edition of the Complete Psychological Works of Sigmund Freud (trans. and ed. J. Strachey), vol. 13: London: Hogarth Press.

Haeckel, E. H. P. A. (1879) The Evolution of Man: A Popular Exposition of the Principal Points of Human Ontogeny and Phylogeny (trans. from the German edition of 1868). London: Beccles.

Jung, C. G. (1953) The Collected Works. London Routledge \& Kegan Paul.

C. A. Sims Suffolk Forensic Services, Forensic Psychology Services, St Clements Hospital, 564 Foxhall Road, Ipswich IP3 8LT, UK

\section{Chromosome 22qII deletion and brain tissue composition}

We thank Eliez \& Blasey (2001) for their kind comments about our paper (van Amelsvoort et al, 2001). However, we disagree that our paper implied that Eliez et al (2000) reported relatively smaller frontal lobe volumes and would like to draw their attention to the following. Normal brain maturation is accompanied by a reduction in cortical grey matter volume and an increase in white matter volume. Myelination typically progresses from posterior to anterior brain regions and occurs relatively late in frontal regions (where it continues into adulthood). Also, the maturational process from adolescence into adulthood is associated with a net volume reduction in frontal regions (Giedd et al, 1999; Sowell et al, 1999), and not a volume increase as Eliez \& Blasey (2001) suggest. Consequently, we interpreted the relatively larger frontal lobe volumes found by Eliez et al (2000) in children and adolescents with velocardio-facial syndrome (VCFS) as compared with controls as possibly being caused by a relative delay in onset of 'maturational' grey matter reduction in VCFS. Our finding of a regional increase in volume of frontal grey matter and decrease in frontal white matter, in the absence of a difference in total frontal lobe (grey and white matter) volume, supports this interpretation and suggests that subtle differences in tissue composition occur which may reflect a delay in maturational processes (van Amelsvoort et al, 2001). Moreover, white matter abnormalities have been reported in VCFS and abnormal myelination could partially explain the abnormal, or delayed, maturational process. Future studies using longitudinal designs across this age span, and newer techniques such as diffusion tensor imaging, should be able to address this issue.

\section{van Amelsvoort, T., Daly, E., Robertson, D., et al (200I) Structural brain abnormalities associated with deletion at chromosome 22ql I. Quantitative neuroimaging study of adults with velo-cardio-facial syndrome. British Journal of Psychiatry, 178, 412-419.}

Eliez, S. \& Blasey, C. M. (200I) Chromosome 22ql deletion and brain structure (letter). British Journal of Psychiatry, 179, 270.

_, Schmitt, J. E., White, C. D., et al (2000) Children and adolescents with velocardiofacial syndrome: a volumetric MRI study. American Journal of Psychiatry, 157 409-415.

Giedd, J. N., Blumenthal, J., Jeffries, N. O., et al (1999) Brain development during childhood and adolescence: a longitudinal MRI study. Nature Neuroscience, 2, 861-863.
Sowell, E. R., Thompson, P. M., Holmes, C. J., et al (1999) In vivo evidence for post-adolescent brain maturation in frontal and striatal regions. Nature Neuroscience, 2, 859-861.

T. van Amelsvoort, K. C. Murphy, D. G. M. Murphy Department of Psychological Medicine, Institute of Psychiatry, De Crespigny Park, London SE5 8AF, UK

\section{Long-term potentiation and changes seen in depression}

Reid \& Stewart (2001) review evidence for a neurobiological basis of depression and it is suggested that brain plasticity plays a major role. These plasticity changes involve neuronal atrophy, neurogenesis, dendrite involution and formation, and long-term potentiation (LTP). Electroconvulsive therapy (ECT) and antidepressants enhance LTP and, as Reid \& Stewart imply, the benefits (and adverse effects) of such treatments may be due to an enhancement or saturation of LTP. We question whether abnormal LTP per se is a critical neurobiological path to the changes seen in depression. We support the view that alterations in structural plasticity, as opposed to LTP, are more critical. Antidepressants, ECT, depression and stress can all modulate neuronal structure and LTP has been shown to be abnormal in models of depression and stress, but it does not follow that abnormal LTP is a prerequisite for these states, even though LTP is accepted to be important in, for example, associative learning.

In studies where LTP has been shown to alter neuronal structure, the increase in synaptic efficacy (assayed electrophysiologically) occurs within seconds to minutes but the earliest detected structural changes take at least 20 minutes (Yuste \& Bonhoeffer, 2001). This time frame also does not correlate with the time required for the effects of antidepressant treatment (including ECT) - structural changes correlate better. Furthermore, although LTP is associated with morphological changes, these do not necessarily contribute to the potentiation (Yuste \& Bonhoeffer, 2001). This casts doubt on the notion that the alterations in LTP are critical to the pathophysiological mechanism. We support the notion that the primary pathology is due to maladaptive neuronal structural change (Vaidya \& Duman, 2001). The most likely reason why LTP can be affected by stress and depression, 